\title{
Crystallochemical Structure of Tourmalines Inferred from Mössbauer Spectroscopy
}

\author{
J. KRACZKA ${ }^{a}$ AND A. PIECZKA ${ }^{b}$ \\ ${ }^{a} \mathrm{H}$. Niewodniczański Institute of Nuclear Physics \\ Radzikowskiego 152, 31-342 Cracow, Poland \\ ${ }^{b}$ University of Mining and Metallurgy \\ Mickiewicza 30, 30-059 Cracow, Poland
}

\begin{abstract}
In the Y octahedra of tourmalines theoretically may occur ions of $\mathrm{Fe}^{2+}$ and $\mathrm{Fe}^{3+}$. The authors discuss Mössbauer measurements and confirm the ordered model of ionic distribution at these sites: the presence of $\mathrm{Fe}^{3+}$ ions in the $\mathrm{Y}$ octahedra and $\mathrm{Al}^{3+}$ ions in the $\mathrm{Z}$ octahedra. The spectra of different tourmalines annealed at temperatures ranging from $873 \mathrm{~K}$ to $1153 \mathrm{~K}$ show that $\mathrm{Fe}^{3+}$ ions can occur in both of these sites. The annealing has changed the symmetry of the neighbourhood of iron ions at the octahedral sites. It has been shown that the doublets with QS $<2.00 \mathrm{~mm} / \mathrm{s}$ should not been attributed to $\mathrm{Fe}^{2+}(\mathrm{Z})$. Also new results corroborating the existence of the iron ions in the mixed valence state in tourmalines have been presented.
\end{abstract}

PACS numbers: $76.80 .+\mathrm{y}$

\section{Introduction}

Tourmalines are borosilicates with a complex structure. Their general crystallochemical formula is $\mathrm{XY}_{3} \mathrm{Z}_{6} \mathrm{~B}_{3} \mathrm{Si}_{6} \mathrm{O}_{27}(\mathrm{O}, \mathrm{OH}, \mathrm{F})_{4}$. $\mathrm{X}$ designates tetrahedral sites occupied mainly by alkali metal cations. $\mathrm{Y}$ and $\mathrm{Z}$ designate octahedral sites, where in the $Y$ octahedra a central ion coordinates four oxygen ions and two $\mathrm{OH}$ groups (or one $\mathrm{OH}$ and one $\mathrm{F}$ ), while in the $\mathrm{Z}$ octahedra it coordinates five oxygen ions and one $\mathrm{OH}$ group. Iron occurs in both of these sites.

Numerous papers on Mössbauer studies of tourmalines present a rather simple interpretation of Mössbauer spectra of these minerals: one doublet of quadrupole splitting attributed to $\mathrm{Fe}^{2+}(\mathrm{Y})$, one doublet to $\mathrm{Fe}^{2+}(\mathrm{Z})$, and one or two doublets attributed to $\mathrm{Fe}^{3+}$ present in either of the two positions [1,2]. During last 
years several papers dealt with more detailed determination of the crystallochemical structure of tourmalines, utilizing not only the Mössbauer method [3-7]. The Mössbauer studies focused mainly on the effects of the 2 nd coordination shell that differentiate Mössbauer spectra within the group of tourmalines and on the possibilities of identification in these spectra the doublets from iron ions in the mixed valence state. It is a prevalent opinion $[3,5,6,8]$ that the model assuming the ordered distribution of ions at the $\mathrm{Y}$ and $\mathrm{Z}$ sites may be applied at least to some types of tourmalines, and this means that the $\mathrm{Z}$ sites are almost always occupied by $\mathrm{Al}$ ions. As some authors accept that $\mathrm{Fe}^{2+}$ can fill both types of octahedra, it seems that every new information relevant may add something significant in this discussion.

\section{Method}

Mössbauer spectroscopy was employed in to study 53 samples of tourmalines from Poland and abroad. Each sample was also a subject to X-ray investigations. Mössbauer samples were prepared as discs with diameters of $2 \mathrm{~cm}^{2}$ and a thickness of $5 \mathrm{mg} \mathrm{Fe} / \mathrm{cm}^{2} . \mathrm{Co}^{57}(\mathrm{Rh})$ with an activity of $25 \mathrm{mCi}$ was the source of $\gamma$ radiation. The measurements were carried out at the room temperature using a constant acceleration spectrometer. The velocity scale of the spectrometer was calibrated with an $\alpha$-Fe foil.

Five samples, appearing as the most interesting, were annealed for $1 \mathrm{~h}$ in air at various temperatures. The degree of oxidation of each sample was checked using the X-ray diffraction (XRD) method and its Mössbauer spectrum recorded at the room temperature.

\section{Results and discussion}

Mössbauer spectra of selected tourmalines are shown in Fig. 1. The spectra can be divided into several types. An almost symmetrical spectrum, associated with $\mathrm{Fe}^{2+}$ ions is presented in Fig. 1A. In Fig. 1B an increasing asymmetry of the spectrum, resulted from the presence of small doublets associated with $\mathrm{Fe}^{3+}$ ions, can be seen. Figures 1C and D present the spectra with distinct, significant lines associated with $\mathrm{Fe}^{3+}$ ions and an additional doublet designated in Fig. 2 as X (its origin will be discussed further in the paper).

From the shapes of the spectra presented in Fig. 1 it becomes obvious that most of them cannot be numerically fitted in the classic way, i.e. assuming a maximum of four doublets associated with $\mathrm{Fe}^{2+}(\mathrm{Y}), \mathrm{Fe}^{2+}(\mathrm{Z}), \mathrm{Fe}^{3+}(\mathrm{Y})$, and $\mathrm{Fe}^{3+}(\mathrm{Z})$. In each of the samples studied the number of doublets, necessary for proper resolution of their spectra and attributable to $\mathrm{Fe}^{2+}$ ions, is higher than two. In the samples whose spectra approximate the spectrum presented in Fig. 2, the number of doublets associated with $\mathrm{Fe}^{2+}$ is four or five and these doublets have their parameters characteristic of the $\mathrm{Fe}^{2+}$ ions in octahedral coordination. While isomer 


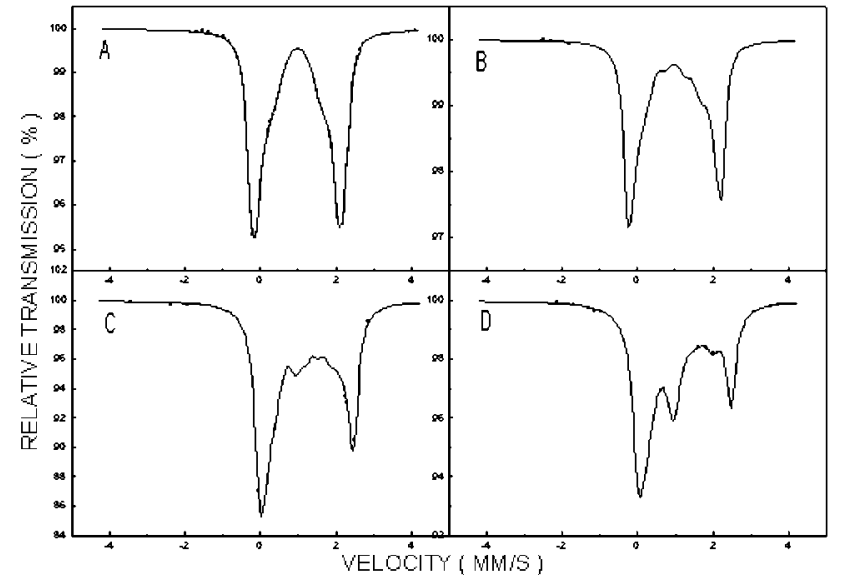

Fig. 1. Mössbauer spectra of various tourmalines.

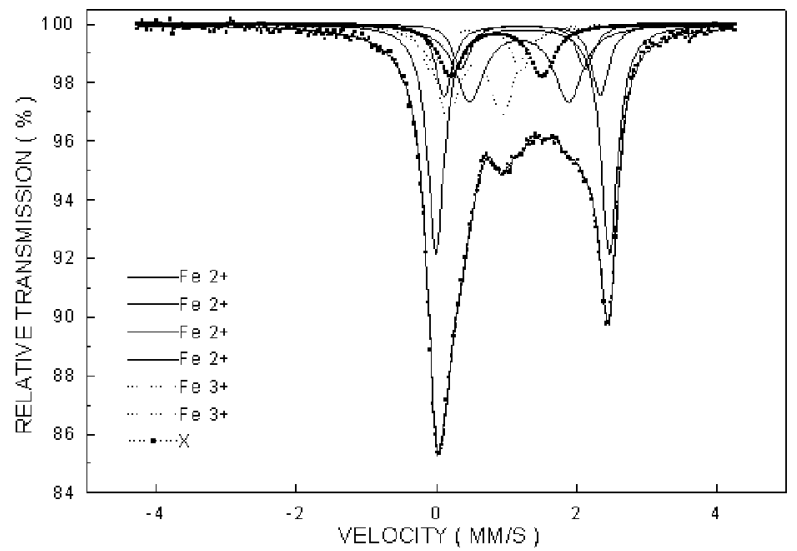

Fig. 2. Seven doublets resolving in the spectrum of sample 36 .

shifts (IS) of these doublets are almost identical in all the samples studied, they significantly differ in their quadrupole splitting (QS) values (Table I). For $\mathrm{Fe}^{2+}$ ions the smaller value of QS indicates a stronger distortion from the ideal local symmetry. If the only reason of the presence of the $\mathrm{Fe}^{2+}$ doublets with various QS values were differences in the elemental structure of the $Y$ and $Z$ octahedra, only two such doublets would have been observed in the Mössbauer spectra. The presence of a higher number of such doublets may be caused by differences within the 2 nd coordination shell (next nearest neighbourhood effect). This effect can be particularly significant for the $\mathrm{Fe}^{2+}$ ions in the $\mathrm{Y}$ octahedra as these three octahedra in the tourmaline structure form an interlinked group and, therefore, the ions situated in the centres of these octahedra are positioned close to each other. For this reason the presence of doublets with higher QS values may be explained by 
TABLE I

Resolutions of Mössbauer spectra of thermally oxidized sample 49. IS — relative to $\alpha$-Fe.

\begin{tabular}{|c|c|c|c|c|c|c|c|}
\hline $\begin{array}{c}\text { Temp. of } \\
\text { annealing } \\
{[\mathrm{K}]}\end{array}$ & $\begin{array}{c}\mathrm{IS} \\
{[\mathrm{mm} / \mathrm{s}]}\end{array}$ & $\begin{array}{c}\text { QS } \\
{[\mathrm{mm} / \mathrm{s}]}\end{array}$ & $\begin{array}{c}S \\
{[\%]}\end{array}$ & $\begin{array}{c}\text { Temp. of } \\
\text { annealing } \\
{[\mathrm{K}]}\end{array}$ & $\begin{array}{c}\mathrm{IS} \\
{[\mathrm{mm} / \mathrm{s}]}\end{array}$ & $\begin{array}{c}\text { QS } \\
{[\mathrm{mm} / \mathrm{s}]}\end{array}$ & $\begin{array}{c}S \\
{[\%]}\end{array}$ \\
\hline \multirow{8}{*}{-} & 1.08 & 2.47 & 30 & \multirow{8}{*}{953} & 1.08 & 2.48 & 13 \\
\hline & 1.08 & 2.17 & 30 & & 1.08 & 2.19 & 16 \\
\hline & 1.09 & 1.86 & 11 & & 1.08 & 1.94 & 6 \\
\hline & 1.08 & 1.53 & 12 & & 1.06 & 1.55 & 9 \\
\hline & 0.35 & 0.36 & 3 & & 1.08 & 1.19 & 8 \\
\hline & 0.76 & 1.30 & 2 & & 0.36 & 0.92 & 20 \\
\hline & & & & & 0.36 & 1.28 & 19 \\
\hline & & & & & 0.70 & 1.39 & 9 \\
\hline \multirow{10}{*}{873} & 1.08 & 2.48 & 22 & \multirow{8}{*}{993} & 1.05 & 2.46 & 3 \\
\hline & 1.08 & 2.18 & 23 & & 1.09 & 2.11 & 4 \\
\hline & 1.09 & 1.92 & 6 & & 1.07 & 1.61 & 6 \\
\hline & 1.08 & 1.55 & 13 & & 1.07 & 1.18 & 4 \\
\hline & 1.08 & 1.11 & 9 & & 0.36 & 0.92 & 36 \\
\hline & 0.53 & 0.91 & 10 & & 0.35 & 1.27 & 43 \\
\hline & \multirow{4}{*}{$\begin{array}{l}0.36 \\
0.72\end{array}$} & 1.27 & 11 & & 0.69 & 1.44 & 4 \\
\hline & & \multirow[t]{3}{*}{1.30} & \multirow[t]{3}{*}{6} & & & & \\
\hline & & & & & 0.35 & 0.92 & 57 \\
\hline & & & & 1153 & 0.35 & 1.26 & 43 \\
\hline
\end{tabular}

differences in the occupancy of theseoctahedral triads by various numbers of $\mathrm{Fe}^{2+}$ ions (one, two or three) plus other ions $\left(\mathrm{Mg}^{2+}, \mathrm{Al}^{3+}\right.$, and even $\mathrm{Ti}^{4+}$ ). The authors showed for several samples of tourmalines that such an explanation is justified [7].

The explanation presented above that relates the occurrence of various $\mathrm{Fe}^{2+}$ doublets not with the differences in the structure of the $\mathrm{Y}$ and $\mathrm{Z}$ octahedra but with the 2nd coordination shell of the $\mathrm{Y}$ site is important in the model of the ordered structure of tourmalines, proposed by several authors $[3,6,7,8]$. According to this model, in the $\mathrm{Z}$ octahedra there should occur almost exclusively $\mathrm{Al}^{3+}$ ions, while the $\mathrm{Fe}^{2+}$ ions should occupy the $\mathrm{Y}$ octahedra.

From such spectra as those presented in Fig. 2, the position of $\mathrm{Fe}^{3+}$ ions in the structure of tourmalines can be inferred. Those spectra show one or two doublets with parameters characteristic of $\mathrm{Fe}^{3+}$ ions in octahedral coordination. Since the intensities of these doublets are usually very low and they are superimposed by much stronger lines of $\mathrm{Fe}^{2+}$-doublets, the only possible conclusion is that they belong to $\mathrm{Fe}^{3+}(\mathrm{Y})$ and/or $\mathrm{Fe}^{3+}(\mathrm{Z})$. Broad lines of these doublets in some spectra 
suggest that they actually represent superposition of several doublets with very low intensities that cannot be resolved in any reasonable way. Annealing of such samples to various temperatures aimed, among others, at increasing their amount of $\mathrm{Fe}^{3+}$. Such a procedure has supplemented so scarce information on these ions, present so far in the literature of the subject.

Literature data indicate that the annealing process is associated with the change of lattice parameters towards the values characteristic of buergerite, which is the tourmaline variety with $\mathrm{Fe}^{3+}$ ions in the $\mathrm{Y}$ octahedra. Such changes take part only in the presence of oxygen, in a neutral atmosphere they are absent. It can be thus assumed that the thermal oxidation of $\mathrm{Fe}^{2+}$ in tourmalines results in deprotonation of their structure according to the following reaction:

$$
4 \mathrm{Fe}^{2+}+4(\mathrm{OH})^{-}+\mathrm{O}_{2}=4 \mathrm{Fe}^{3+}+4 \mathrm{O}^{2-}+2 \mathrm{H}_{2} \mathrm{O} .
$$

In consequence, $\mathrm{Fe}^{3+}$ ions should be present after oxidation in the same lattice sites as were initially occupied by $\mathrm{Fe}^{2+}$ ions.

In the spectra of all the samples annealed two distinct doublets appear, whose intensity increases with annealing temperature (Fig. 3). At temperatures in

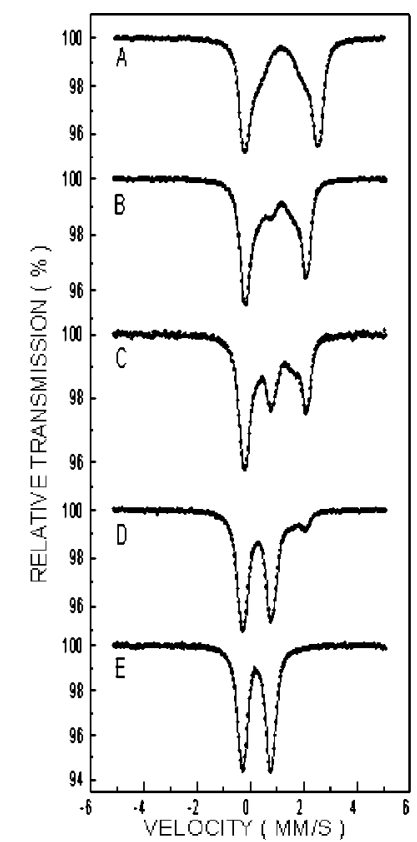

Fig. 3. Mössbauer spectra of sample 49 before annealing (A) and after annealing at temperatures: $873 \mathrm{~K}(\mathrm{~B}), 953 \mathrm{~K}(\mathrm{C}), 993 \mathrm{~K}(\mathrm{D}), 1153 \mathrm{~K}(\mathrm{E})$. 
the range of $1000 \mathrm{~K}$ the spectra show the presence of only $\mathrm{Fe}^{3+}$-doublets. The lines of the doublets are widened, but their shape is symmetrical. The values of IS of these doublets are similar, characteristic of $\mathrm{Fe}^{3+}$ in octahedral coordination, but quadrupole splittings of the doublets vary. In the case of $\mathrm{Fe}^{3+}$ ions, the electric field gradient (EFG) results totally from the asymmetric neighbourhood of these ions, hence the doublets with lower QS values correspond to the sites with the symmetry closer to the perfect one. Considering this and also taking into account the QS values of the $\mathrm{Fe}^{3+}$-doublets observed in various samples (Table II), the following conclusions can be made.

TABLE II

Parameters of $\mathrm{Fe}^{3+}$-doublets. $S\left(\mathrm{Fe}^{3+}\right)$ and $S(\mathrm{X})$-relative intensities of $\mathrm{Fe}^{3+}$ doublets and mixed valence state doublet, $\mathrm{Al}^{3+}-\mathrm{Al}^{3+}$ content on the basis of $31(\mathrm{O}, \mathrm{OH}, \mathrm{F})$, IS - relative to $\alpha$-Fe.

\begin{tabular}{c|c|c|c|c|c|c}
\hline \hline Sample & $\begin{array}{c}\text { IS } \\
{[\mathrm{mm} / \mathrm{s}]}\end{array}$ & $\begin{array}{c}\mathrm{QS} \\
{[\mathrm{mm} / \mathrm{s}]}\end{array}$ & $\begin{array}{c}S\left(\mathrm{Fe}^{3+}\right) \\
{[\%]}\end{array}$ & $\begin{array}{c}S(\mathrm{X}) \\
{[\%]}\end{array}$ & $\mathrm{Fe}^{3+} / \mathrm{Fe}^{2+}$ & $\mathrm{Al}^{3+}$ \\
\hline 49 & 0.35 & 0.36 & 3 & 2 & 0.04 & 6.505 \\
\hline 48 & 0.36 & 0.39 & 3 & 0 & 0.03 & 6.550 \\
\hline $\mathrm{N} 5$ & 0.35 & 0.40 & 4 & 7 & 0.05 & 6.732 \\
\hline 41 & 0.42 & 0.74 & 49 & 26 & 0.59 & 5.513 \\
\hline 42 & 0.42 & 0.74 & 49 & 24 & 0.61 & 5.464 \\
\hline 47 & 0.40 & 0.80 & 10 & 29 & 0.25 & 5.765 \\
\hline 36 & 0.39 & 0.78 & 17 & 11 & 0.30 & 6.182 \\
& 0.41 & 1.28 & 7 & & & \\
\hline 37 & 0.41 & 0.76 & 14 & 10 & 0.26 & 6.231 \\
& 0.39 & 1.25 & 7 & & &
\end{tabular}

1. In Al-poor samples $(41,42,47)$, where the amount of $\mathrm{Al}$ is insufficient to fill all octahedra, some of the $\mathrm{Z}$ sites are being filled with $\mathrm{Fe}^{3+}$. The parameters of the distinct $\mathrm{Fe}^{3+}$-doublet observed in these samples are characterized by rather high QS values $(0.74-0.80 \mathrm{~mm} / \mathrm{s})$. This value is accepted in further calculations, i.e. when the spectra of other samples are being interpreted, as the characteristic of the $\mathrm{Fe}^{3+}(\mathrm{Z})$.

2. In samples in which $\mathrm{Fe}^{3+}$ occurs in very low amounts, there is only one $\mathrm{Fe}^{3+}$-doublet with low values of QS. This doublet can thus be attributed to $\mathrm{Fe}^{3+}$ ions at the $\mathrm{Y}$ sites.

3. In the case of some samples with intermediate $\mathrm{Fe}^{3+}$ contents $(36,37)$, the interpretation of $\mathrm{Fe}^{3+}$-doublets is more complex. In the spectra of these samples two $\mathrm{Fe}^{3+}$-doublets appear. One of them, with a higher intensity (QS $=0.76 \div 0.78 \mathrm{~mm} / \mathrm{s}$ ) should be attributed to $\mathrm{Fe}^{3+}(\mathrm{Z})$. Since the amount 
of $\mathrm{Al}$ in these samples is higher than required to fill the $\mathrm{Z}$ sites, it can be concluded that the excess of $\mathrm{Al}^{3+}$ occupy other positions than $\mathrm{Z}$. Prior to Mössbauer measurements of the samples annealed, the interpretation of the weak $\mathrm{Fe}^{3+}$-doublet with $\mathrm{QS}=1.25 \div 1.28 \mathrm{~mm} / \mathrm{s}$ was impossible. After the annealing, the origin of this doublet may be linked to the $\mathrm{Fe}^{3+}$ ions in strongly deformed $\mathrm{Y}$ octahedra.

4. In the course of annealing Al-rich samples, in which $\mathrm{Fe}^{2+}$ occupied initially only the $\mathrm{Y}$ sites, these ions were gradually replaced by $\mathrm{Fe}^{3+}$ ions (the effect of oxidation). In the spectra of samples annealed, the doublet with QS = $0.40 \mathrm{~mm} / \mathrm{s}$ that is characteristic of $\mathrm{Fe}^{3+}(\mathrm{Y})$ in samples not subjected to annealing disappears already at $873 \mathrm{~K}$, while two doublets with higher QS values become visible. It is the proof that $\mathrm{Fe}$ ions occupy after annealing more deformed sites than they do in the tourmalines before annealing. The presence of only two doublets (and not four or five, as it is in samples prior to annealing) confirms that the neighbourhood of these ions is less diversified.

In some samples of tourmalines, i.e. those revealing the spectra approximating the spectrum shown in Figs. $1 \mathrm{C}$ and D, there is a doublet corresponding to that denoted $\mathrm{X}$. The contribution of the area under this doublet is higher in the samples with a higher $\mathrm{Fe}^{3+} / \mathrm{Fe}^{2+}$ ratio. Its IS distinctly differs from the IS values attributed to $\mathrm{Fe}^{2+}$ and $\mathrm{Fe}^{3+}$ ions in octahedral coordination, being in all the samples studied equal almost perfectly to their arithmetic mean. During measurements of spectra of samples annealed, it was previously proved in a single sample that the intensity of this doublet is the highest when the $\mathrm{Fe}^{2+} / \mathrm{Fe}^{3+}$ ratio approximates 1 [9]. Now, the measurements of all the samples annealed have revealed similar changes of the intensity in question.

Measurements of the samples annealed indicate also that the model in which the doublets with $\mathrm{QS}>2.00 \mathrm{~mm} / \mathrm{s}$ are attributed to $\mathrm{Fe}^{2+}(\mathrm{Y})$, and those with $\mathrm{QS}>2.00 \mathrm{~mm} / \mathrm{s}$ to $\mathrm{Fe}^{2+}(\mathrm{Z})$, is not correct. If the model were true, the ratio of intensities of the doublets in samples totally oxidized $u$ would have been close to $r=a / b$, where $a$ denotes the intensity of the $\mathrm{Fe}^{2+}$-doublets with QS $>2.00 \mathrm{~mm} / \mathrm{s}$ and $b$ the total intensity of $\mathrm{Fe}^{2+}$-doublets with QS $<2.00 \mathrm{~mm} / \mathrm{s}$ in the initial (i.e. not annealed) sample. In the spectra of all totally oxidized samples the $u$ value is close to 1 , being several times smaller than $r$.

\section{Conclusions}

Mössbauer spectra of tourmalines should be numerically and physically resolved accepting a higher number of doublets (even up to eight). Mössbauer measurements can confirm that the model of the ordered distribution of ions at the $\mathrm{Y}$ and $\mathrm{Z}$ sites is correct for both $\mathrm{Al}$-rich and $\mathrm{Al}$-poor tourmalines. Analysing results of measurements of numerous natural samples and several samples annealed at various temperatures, it can be stated that $\mathrm{Fe}^{2+}$ ions occupy the $\mathrm{Y}$ sites, while 
$\mathrm{Fe}^{3+}$ ions are present both in the $\mathrm{Y}$ and $\mathrm{Z}$ sites. Annealing of tourmaline samples results in the change of the symmetry in the neighbourhood of the octahedral iron ions. The results of measurements carried out on five annealed samples in this study provide further proofs on the occurrence of the mixed valence state of iron in tourmalines.

This work was partly supported by the State Committee for Scientific Research (Poland), grant No. 6 P04D 03716.

\section{References}

[1] M. deCoster, H. Pollack, S. Amelinckx, Phys. Status Solidi 3, 283 (1963).

[2] E. Hermon, E.J. Simkin, G. Donnay, W.B. Muir, Tschermaks Mineral. Petrogr. Mitt. 19, 124 (1973).

[3] J.D. Grice, T.S. Ercit, N. Jb. Miner. Abh 165, 245 (1993).

[4] F.C. Hawthorne, D.J. MacDonald, P.C. Burns, Am. Mineral. 78, 265 (1993).

[5] Y. Fuchs, M. Lagache, J. Linares, Am. Mineral. 83, 525 (1998).

[6] V. Kahlenberg, B. Velickov, Eur. J. Min. 12, 947 (2000).

[7] A. Pieczka, J. Kraczka, W. Zabiński, J. Czech. Geol. Soc. 43, 1-2, 69 (1998).

[8] J. Kraczka, A. Pieczka, Mol. Phys. Rep. 30, 80 (2000).

[9] A. Pieczka, Eur. J. Min. 12, 589 (2000). 